\title{
Green synthesis and evaluation of silver nanoparticles as adjuvant in rabies veterinary vaccine
}

This article was published in the following Dove Press journal:

International Journal of Nanomedicine

29 July 2016

Number of times this article has been viewed

\author{
Vahid Asgary ${ }^{1,2}$ \\ Alireza Shoari' \\ Fahimeh Baghbani-Arani ${ }^{3}$ \\ Seyed Ataollah Sadat \\ Shandiz ${ }^{4}$ \\ Mohammad Sadeq \\ Khosravy ${ }^{5}$ \\ Alireza Janani' \\ Razieh Bigdeli ${ }^{6}$ \\ Rouzbeh Bashar \\ Reza Ahangari Cohan ${ }^{1,7}$ \\ 'Virology Research Group, \\ Department of Rabies, Pasteur \\ Institute of Iran, ${ }^{2}$ Department of \\ Immunology, School of Medicine, \\ Tehran University of Medical Sciences, \\ Tehran, ${ }^{3}$ Department of Genetics and \\ Biotechnology, School of Biological \\ Science, Varamin-Pishva Branch, \\ Islamic Azad University, Varamin, \\ ${ }^{4}$ Young Researchers and Elite Club, \\ East Tehran Branch, Islamic Azad \\ University, ${ }^{5}$ Department of Laboratory \\ of Animal Sciences, Pasteur Institute \\ of Iran, ${ }^{6}$ Department of Genetic, \\ Science and Research Branch, Islamic \\ Azad University, ${ }^{7} \mathrm{New}$ Technologies \\ Research Group, Department of Pilot \\ Nanobiotechnology, Pasteur Institute \\ of Iran, Tehran, Iran
}

Correspondence: Reza Ahangari Cohan New Technologies Research Group, Department of Pilot Nanobiotechnology, Pasteur Institute of Iran, No 69, 12th Farvardin Ave, Tehran 131694355I, Iran Tel +98 2I 66176745

$\mathrm{Fax}+982166976717$

Email cohan_r@yahoo.com
Background: Green synthesis of nanoparticles by plant extracts plays a significant role in different applications. Recently, several studies were conducted on the use of nanoparticles as adjuvant. The main aim of this study was to evaluate green synthesized silver nanoparticles (AgNPs) as adjuvant in rabies veterinary vaccine and compare the results with the existing commercially available alum adjuvant.

Materials and methods: In the current study, AgNPs were prepared by the reduction of aqueous silver nitrate by leaf extract of Eucalyptus procera. The formation of AgNPs was confirmed by ultraviolet (UV)-visible spectrophotometer, scanning electron microscopy, dynamic light scattering, and X-ray diffraction analysis. Then, different amounts of AgNPs $(200 \mu \mathrm{g}$, $400 \mu \mathrm{g}, 600 \mu \mathrm{g}$, and $800 \mu \mathrm{g}$ ) were added to $1 \mathrm{~mL}$ of inactivated rabies virus. The loaded vaccines $(0.5 \mathrm{~mL})$ were injected intraperitoneally into six Naval Medical Research Institute mice in each group on days 1 and 7. On the 15th day, the mice were intracerebrally challenged with $0.03 \mathrm{~mL}$ of challenge rabies virus (challenge virus strain-11, 20 lethal dose $\left[20 \mathrm{LD}_{50}\right]$ ), and after the latency period of rabies disease in mice ( 5 days), the mice were monitored for 21 days. Neutralizing antibodies against rabies virus were also investigated using the rapid fluorescent focus inhibition test method. The National Institutes of Health test was performed to determine the potency of optimum concentration of AgNPs as adjuvant. In vitro toxicity of AgNPs was assessed in L929 cell line using MTT assay. In addition, in vivo toxicity of AgNPs and AgNPsloaded vaccine was investigated according to the European Pharmacopeia 8.0.

Results: AgNPs were successfully synthesized, and the identity was confirmed by UV-visible spectrophotometry and X-ray diffraction analysis. The prepared AgNPs were spherical in shape, with an average size of $60 \mathrm{~nm}$ and a negative zeta potential of $-14 \mathrm{mV}$ as determined by dynamic light scattering technique. The highest percentage of viability was observed at $15 \mathrm{mg} / \mathrm{kg}$ and $20 \mathrm{mg} / \mathrm{kg}$ of AgNPs-loaded vaccine concentrations after injecting into the mice. The calculated potencies for alum-containing vaccine and AgNPs-loaded vaccine (dose $15 \mathrm{mg} / \mathrm{kg}$ ) were 1.897 and 1.303 , respectively. MTT assay demonstrated that alum at the concentration of $10 \mathrm{mg} / \mathrm{mL}$ was toxic, but AgNPs were not toxic. The in vivo toxicity also elucidated the safety of AgNPs and AgNPs-loaded vaccine in mice and dogs, respectively.

Conclusion: In the current study, for the first time, the adjuvanticity effect of green synthesized AgNPs on veterinary rabies vaccine potency with no in vivo toxicity was elucidated according to the European Pharmacopeia 8.0.

Keywords: green synthesis, nanoparticles, rabies virus, adjuvant

\section{Introduction}

Rabies is an acute viral encephalomyelitis caused by a virus belonging to the Rhabdoviridae family. ${ }^{1}$ According to the official reports, $>60,000$ people annually 
die of rabies, with $99 \%$ of them from Asia and Africa. ${ }^{2,3}$ Rabies is a preventable disease, and as a major control strategy, vaccination is recommended by the World Health Organization (WHO). The vaccine is used in two distinct situations that include pre- and postexposure treatments. The protective function is the production of neutralizing antibodies, either IgM or IgG, which are able to prevent the entry of virus into cells. ${ }^{4}$ The vaccine is prepared by inactivation of rabies virus to prevent disease either before or after exposure to the virus. Since animals play a significant role in the spread of the disease, vaccination of livestock and wild life is proven to be a common way of controlling the disease in developed countries. In this regard, with regular vaccination of animals, human rabies has been controlled in Europe. ${ }^{5}$

To improve the effectiveness of rabies veterinary vaccines, aluminum hydroxide (alum) is used. ${ }^{6}$ Alum is one of the most common adjuvants, and aluminum compounds are widely used in the manufacture of many vaccines. Although, alum enhances immune response, some disadvantages, such as destructive effects on the local tissues (necrosis), prolonged inflammation causing severe irritation at the site of injection, provoking only $\mathrm{T}$ helper 2 response, weak cellular immune response, and unwanted $\mathrm{IgE}$ reactions, restrict its application in vaccine formulations. ${ }^{7-9}$ Moreover, it has been shown that aluminum compounds increase the level of unwanted homocytotropic antibodies in animal species. ${ }^{10}$ Moreover, alum-based vaccines are not effective in producing antiviral responses. Therefore, new adjuvants for the enhancement of immunogenicity of weak antigens, with lower side effects, long-term immune stimulation, and simultaneous stimulation of humoral, cellular, and mucosal responses, are required. Recent progresses in the field of nanotechnology, especially in producing particular size and shape of metal nanoparticles, are leading to the development of a variety of different applications. One feature of nanoparticles is the capability of trapping or capturing molecules such as proteins and nucleic acids; hence, promising methods for antigen delivery and improving the function of the immune system by selection of targeting antigen-presenting cells are provided. As regards, delivery of antigens to antigen-presenting cells, in particular, dendritic cells, and their stimulation are important issues in the development and improvement of vaccine potency; hence, vaccination systems based on nanoparticles create opportunities for controlled delivery of antigens to desired immune cells. ${ }^{11}$ Recently, several studies were conducted on the use of nanoparticles as adjuvant. It was shown that nanoparticles such as silver, gold, and calcium phosphate enhance the immunogenicity of antigens. ${ }^{10,12,13}$ Despite other applications of nanoparticles, they are also used as immune potentiators. For example, nanoparticles such as polylactide-co-glycolide have been used to enhance the immune responses against several antigens. ${ }^{14,15}$ Moreover, in a recent study, the stimulatory effects of silver nanoparticles (AgNPs) on immune response to albumin was elucidated, which showed the ability to enhance the immune response to weak antigens. ${ }^{13}$

Conventionally, nanoparticles are prepared by physicochemical techniques, including chemical vapor deposition, physical vapor deposition, grinding systems, and solvothermal synthesis. ${ }^{16}$ These approaches usually need high-cost instruments, and they are performed under dangerous conditions using hazardous reagents. Some of these procedures also have complications such as instability and aggregation of the synthesized particles. Currently, green synthesis of nanoparticles has been exponentially used because of the lower cost of production as well as the simplicity of synthesis.

Given the potential effects of the nanoparticles as adjuvants and their easy synthesis using green chemistry, AgNPs produced by Eucalyptus procera were evaluated to enhance the immune response against inactivated rabies virus and the results were compared with the existing commercially available alum adjuvant.

\section{Materials and methods Green synthesis of AgNPs}

The preparation method of AgNPs was described earlier. ${ }^{17}$ Fresh E. procera leaves were shade dried at room temperature (RT) and powdered using a mortar and pestle. Then, $50 \mathrm{~g}$ of the dried powder was weighed and boiled in $500 \mathrm{~mL}$ deionized water for 2 hours and then filtered through Whatman grade 1 filter paper. For synthesis of AgNPs, $6 \mathrm{~mL}$ of the extract was added to $100 \mathrm{~mL}$ of $0.01 \mathrm{mM} \mathrm{AgNO}_{3}$ (EMD Millipore, Billerica, MA, USA) aqueous solution and stirred gently at RT. This mixture was incubated until the colorless solution converted into dirty brown color, which revealed the formation of AgNPs. Then, the solution was centrifuged at $13,000 \times g$ for 20 minutes, and the pellet was washed three times with distilled water. AgNPs were resuspended in ethanol (EMD Millipore), dried at $75^{\circ} \mathrm{C}$ for 120 minutes, and stored at $4^{\circ} \mathrm{C}$ for a few days, and subsequent procedures were performed immediately. No instability was observed during the incubation.

\section{Characterization and identification of AgNPs}

Optical absorption spectra of AgNPs were analyzed using an Epoch UV-Vis (UV-visible) spectrophotometer (BioTek, Bad Friedrichshall, Germany) within a range of 300-700 nm 
at RT. The morphology of AgNPs was investigated by scanning electron microscopy (SEM) (KYKY Technology Development Ltd., Beijing, People's Republic of China). The powder samples were coated by gold film for loading the dried particles on the SEM instrument. The gold coating was performed by a Sputter Coater model SCD005 made by BAL-TEC (Pfäffikon ZH, Switzerland), and the images were captured at desired magnification. The size distribution profile and charge quantification of the synthesized AgNPs samples were evaluated by dynamic light scattering particle size analyzer and zeta potential analyzer (Malvern Zetasizer Nano-ZS), respectively. X-ray diffraction (XRD) measurement of the produced AgNPs was carried out using X-ray diffractometer instrument (Rigaku D/max $2500 \mathrm{~V}$ ) in the angle range of $10^{\circ} \mathrm{C}-110^{\circ} \mathrm{C}$ at $2 \theta$ and scan axis $2: 1$ sym.

\section{The adjuvanticity of AgNPs}

Different amounts of AgNPs $(200 \mu \mathrm{g}, 400 \mu \mathrm{g}, 600 \mu \mathrm{g}$, and $800 \mu \mathrm{g}$ ) were added to $1 \mathrm{~mL}$ of inactivated rabies virus (Lot No 92-1; Pasteur Institute of Iran, Tehran, Iran) under biological safety class II laminar hood in sterile conditions. The resulting mixtures were gently stirred at $4^{\circ} \mathrm{C}$ on a magnetic stirrer overnight. The loaded vaccines $(0.5 \mathrm{~mL})$ were injected intraperitoneally into six Naval Medical Research Institute (NMRI) mice in each group on days 1 and 7 for immunization assessment. Inactivated rabies virus and commercial vaccine containing alum adjuvant (Lot No 92-1; Pasteur Institute of Iran) were injected as negative and positive controls, respectively. On the 14th day, blood samples were collected from the ocular vein and sera (at least $100 \mu \mathrm{L}$ ) were used for the determination of raised neutralizing antibodies. On the 15 th day, the mice were intracerebrally challenged with $0.03 \mathrm{~mL}$ of challenge virus strain-11 (CVS-11, 20 lethal dose $\left.[\mathrm{LD}]_{50}\right)$, and after the latency period of rabies disease in mice ( 5 days) the mice were monitored for 21 days. Any death was assessed by fluorescent antibody test (FAT) on dead mouse brains using fluorescein isothiocyanate (FITC)conjugated anti-nucleocapsid polyclonal antibodies (Bio-Rad Laboratories Inc., Hercules, CA, USA) and a fluorescence microscope (E-200; Nikon Corporation, Tokyo, Japan). The presence of Negri bodies in the neuron cells confirmed the rabies disease.

\section{Neutralizing antibody titration by rapid fluorescent focus inhibition test}

Neutralizing antibodies were measured by rapid fluorescent focus inhibition test (RFFIT). The isolated sera were inactivated by incubation at $56^{\circ} \mathrm{C}$ for 30 minutes and threefold serial dilutions of reference (WHO reference) and sample sera were prepared in minimum essential media in triplicates. Subsequently, $50 \mu \mathrm{L}$ of CVS-11 (50 focus forming dose ${ }_{50}$; Pasteur Institute of Iran), sufficient to infect $80 \%$ of cells in each well, was added to each well and incubated at $37^{\circ} \mathrm{C}$ for 1 hour. Minimum essential media instead of CVS-11 and phosphate buffer saline (PBS) instead of serum were used as negative and positive controls, respectively. Approximately $50 \mu \mathrm{L}$ of BSR cell suspension (a clone of baby hamster kidney cells; Pasteur Institute of Iran) in minimum essential media supplemented with $10 \%$ fetal bovine serum $\left(5 \times 10^{4}\right.$ cells/well $)$ was added to each well and incubated overnight at $37^{\circ} \mathrm{C}$ in $5 \% \mathrm{CO}_{2}$. The plates were rinsed three times with PBS and fixed using $80 \%$ cold acetone for 30 minutes at $4^{\circ} \mathrm{C}$. Finally, the plates were stained with $50 \mu \mathrm{L}$ FITC-conjugated anti-nucleocapsid polyclonal antibody, and the percentage of the infection was determined by fluorescent microscopy. The neutralizing antibody titers were calculated using Reed and Muench method, a simple method for estimating $50 \%$ end points. ${ }^{18}$

\section{Determination of vaccine potency using National Institutes of Health test}

The National Institutes of Health (NIH) test is a gold standard method according to WHO, British, European, and US Pharmacopeia for measuring the potency of adjuvants for rabies virus vaccine. ${ }^{19-22}$ According to the results of the adjuvanticity test, the concentration of $15 \mathrm{mg} / \mathrm{kg}(300 \mu \mathrm{g}$ AgNPs per injection dose) was used for the NIH test. Serial dilutions (1:5, $1: 25,1: 125$, and $1: 625$ ) of the test and the reference (Rabipur, India, Lot No 2078) vaccines were prepared in the NIH buffer (0.83 $\mathrm{g} \mathrm{NaCl}, 0.11 \mathrm{~g} \mathrm{Na}_{2} \mathrm{HPO}_{4}$, and $0.027 \mathrm{~g} \mathrm{KH}_{2} \mathrm{PO}_{4}$ in $100 \mathrm{~mL}$ of distilled water adjusted to $\mathrm{pH} 4.7$ ), and $0.5 \mathrm{~mL}$ of each dilution was intraperitoneally injected into ten NMRI mice (20 g; Pasteur Institute of Iran) on days 1 and 7. On the 14th day, the mice were intracerebrally challenged with $0.03 \mathrm{~mL}$ of challenge rabies virus strain (CVS-11, $\left.20 \mathrm{LD}_{50}\right)$. For the determination of median $\mathrm{LD}_{50}$ (the amount of challenge virus to kill $50 \%$ of the mice population), $0.03 \mathrm{~mL}$ of each CVS-11 dilutions $\left(10^{-4}, 10^{-5}, 10^{-6}\right.$, and $\left.10^{-7}\right)$ was injected intracerebrally into ten mice and $\mathrm{LD}_{50}$ was determined using Reed and Muench method. In addition, one group of mice was injected intracerebrally with $0.03 \mathrm{~mL}$ of the test vaccine for inactivity test. After the latency period of rabies disease in mice ( 5 days), they were monitored and the number of sick, paralyzed, or dead animals was recorded for 21 days. To confirm the mice deaths from rabies virus, FAT method was performed on mouse brains to detect Negri bodies (containing viral nucleoprotein). Finally, the mortality of the vaccinated mice with the reference and test vaccines was determined, and the potency was calculated by Probit 
method using Bioassay Assist software Version 2.0 (National Institute of Infectious Diseases (NIID), Tokyo, Japan).

\section{In vitro toxicity assay of the synthesized AgNPs}

L929 cell line (American Type Culture Collection TIB-67) was cultured in RPMI 1640 supplemented with 10\% fetal bovine serum and $1 \mathrm{X}$ Pen-Strep (Thermo Fisher Scientific, Waltham, MA, USA) at $37^{\circ} \mathrm{C}$ in $5 \% \mathrm{CO}_{2}$. For assay, 5,000 cells/well were cultured in a 96-well microplate (Thermo Fisher Scientific) and incubated overnight at $37^{\circ} \mathrm{C}$ in $5 \% \mathrm{CO}_{2}$. Approximately $100 \mu \mathrm{L}$ of different concentrations of AgNPs $\left(10^{-3} \mathrm{mg} / \mathrm{mL}\right.$, $10^{-2} \mathrm{mg} / \mathrm{mL}, 10^{-1} \mathrm{mg} / \mathrm{mL}, 10^{0} \mathrm{mg} / \mathrm{mL}$, and $10^{1} \mathrm{mg} / \mathrm{mL}$ ) was added to each well in sextuplicate and incubated for 24 hours at $37^{\circ} \mathrm{C}$. Then, $100 \mu \mathrm{L}(0.05 \mathrm{mg} /$ well $)$ of MTT (Sigma-Aldrich Co., St Louis, MO, USA) was added to each well and incubated for 4 hours at $37^{\circ} \mathrm{C}$. The supernatants were removed, $100 \mu \mathrm{L}$ of dimethyl sulfoxide (Sigma-Aldrich Co.) was added to each well, and the reaction was read at $570 \mathrm{~nm}$ and $630 \mathrm{~nm}$ using a spectrophotometer. All the data were analyzed with one-way ANOVA statistical test using SPSS software Version 16.0 (SPSS Inc., Chicago, IL, USA) and $P$-value $<0.05$ was considered a significant difference between groups.

\section{Animal storage conditions}

All the animals were housed at $\mathrm{RT}\left(20^{\circ} \mathrm{C}-23^{\circ} \mathrm{C}\right)$ on a 12 -hour light/dark cycle, with unlimited access to food and water, and adapted for 1 week before the tests. Animal experiments were approved by the ethical committee of Pasteur Institute of Iran and performed based on the ethical standards formulation in the Declaration of Helsinki.

\section{Abnormal toxicity test for the synthesized AgNPs}

Abnormal toxicity test was performed for the green synthesized AgNPs according to the European Pharmacopeia 8.0. Outbred female CD1 mice (4-5 weeks old with a body weight range of 17-24 g) supplied by the Pasteur Institute of Iran were used in this study. ${ }^{23}$ Briefly, $300 \mu \mathrm{g}$ of AgNPs was dissolved in $0.5 \mathrm{~mL}$ of a $9 \mathrm{~g} / \mathrm{L}$ sterile and pyrogen-free sodium chloride solution $\mathrm{R}$ and then injected intravenously into five healthy female CD1 mice. As a control, $0.5 \mathrm{~mL}$ of a $9 \mathrm{~g} / \mathrm{L}$ sterile and pyrogen-free sodium chloride $\mathrm{R}$ solution was injected intravenously into another five mice. All the mice were monitored for abnormal reaction, signs of illness, and weight loss for 24 hours after the time of injection. ${ }^{24}$ A two-tailed unpaired $t$-test was used for calculating $P$-value difference between the test and control data.

\section{Safety test on AgNPs-loaded rabies vaccine for veterinary use}

Safety test on AgNPs-loaded rabies vaccine for veterinary use was carried out according to European Pharmacopeia 8.0. Two healthy female dogs (Skye Terrier breed, 12 weeks old) that did not have antibodies against rabies virus were used. Briefly, the animals were examined by a veterinarian and confirmed to be healthy. The body temperatures were recorded for 3 days prior to administration of the vaccine, and the mean temperature was used as baseline. Then, a double dose of the AgNPs-loaded rabies vaccine was intramuscularly injected, and the animals were monitored at least daily for signs of abnormal local and systemic reactions for 14 days after administration. ${ }^{25}$ In addition, the body temperatures were monitored at 0 hour, 4 hours, and 4 days after administration. ${ }^{26}$

\section{Results}

\section{Characterization of the synthesized AgNPs}

The identity, size, and shape of the green synthesized AgNPs were analyzed by UV-Vis spectrophotometry, XRD, SEM, and dynamic light scattering techniques. The UV-Vis spectrophotometer proved to be a very useful technique for the analysis of some metal nanoparticles. Reduction of AgNPs was observed based on the surface plasmon resonance peak at $438 \mathrm{~nm}$ by using UV-Vis spectroscopy (Figure 1). No additional peaks were obtained in the spectrum which confirms that the synthesized products are Ag only.

The morphology of nanoparticles was evaluated by SEM. Figure 2 shows a microscopic image of the synthesized AgNPs. Point-to-point study of AgNPs by SEM reveals that the sizes of the nanoparticles vary and are in a range of 50-70 nm.

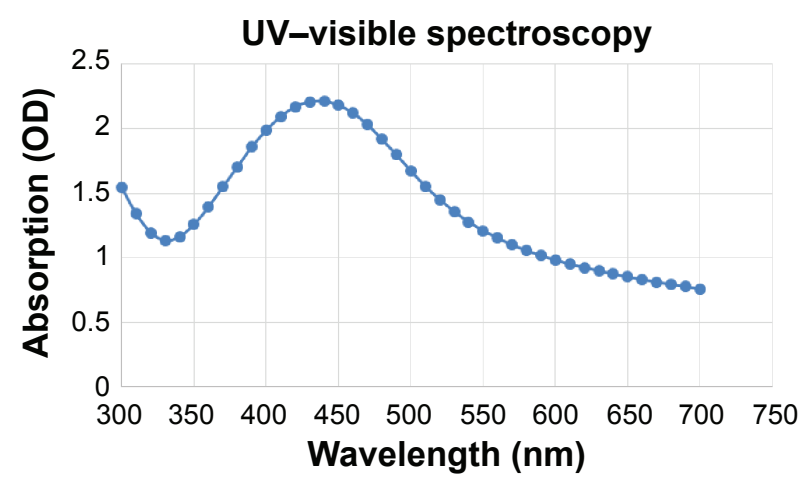

Figure I UV-visible absorption spectrum of green synthesized AgNPs. Abbreviations: AgNPs, silver nanoparticles; OD, optical density; UV, ultraviolet. 


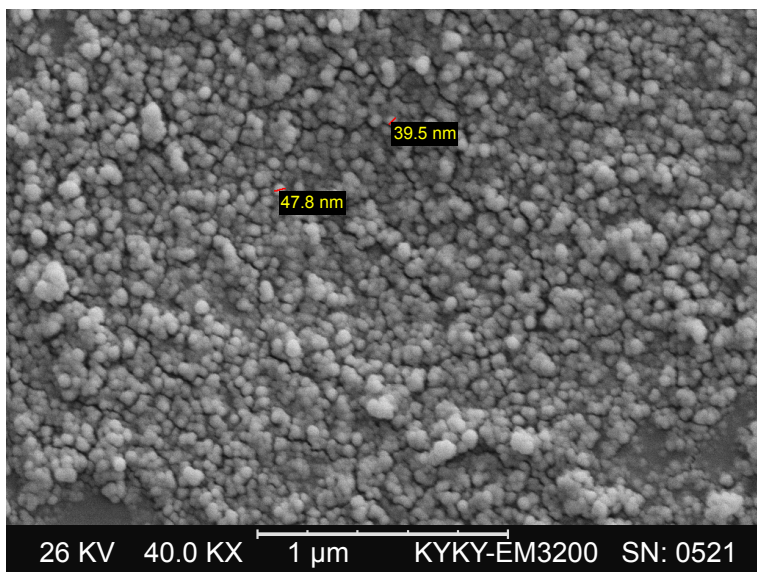

Figure 2 SEM imaging of green synthesized AgNPs.

Abbreviations: AgNPs, silver nanoparticles; SEM, scanning electron microscopy.

The size and zeta potential of AgNPs were also determined using Malvern Zetasizer Nano-ZS (Figure 3). Size distribution profile of the biosynthesized AgNPs showed the particles with a mean size of $\sim 63 \mathrm{~nm}$. The zeta potential of the biosynthesized AgNPs was measured as $-14.9 \mathrm{mV}$.

AgNPs were characterized by XRD analysis for the investigation of their composition and purity. Figure 4 shows XRD patterns of AgNPs synthesized by plant leaves extract. The obtained characteristic diffraction peaks in this XRD pattern were observed at $2 \theta, 38.4,44.5$, and 64.8, which are assigned to the (111), (200), and (220) crystallographic planes of face-centered cubic structure for the silver powder sample, respectively (Joint Committee on Powder Diffraction Standards file No 04-0783). No additional diffraction peaks were observed other than the characteristic peak of the silver structure showing the purity of synthesized AgNPs.

\section{The adjuvanticity analysis of AgNPs}

To analyze the adjuvanticity of the synthesized AgNPs, different amounts of AgNPs were mixed to inactivated rabies virus and injected intraperitoneally into six NMRI mice.

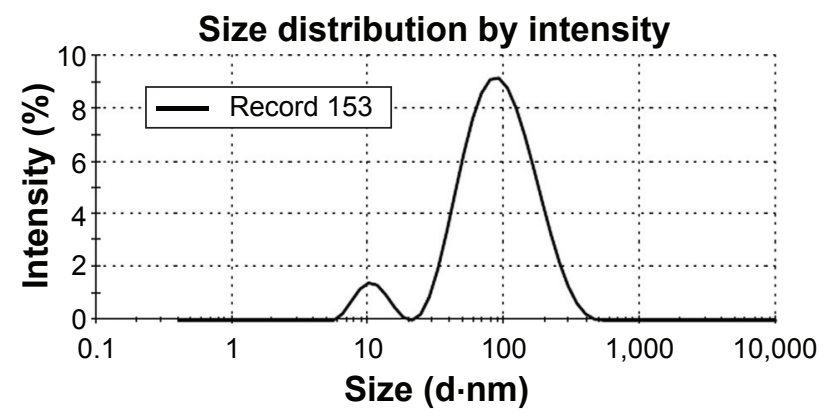

Figure 3 The size distribution of green synthesized AgNPs using DLS technique. Abbreviations: AgNPs, silver nanoparticles; DLS, dynamic light scattering.

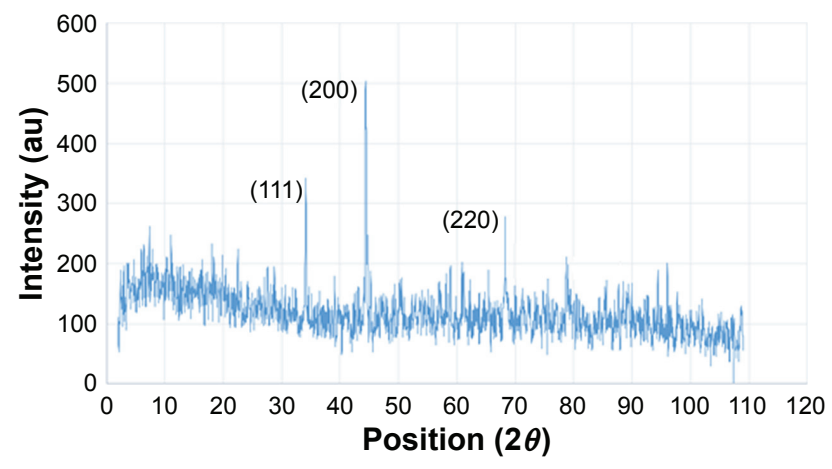

Figure 4 XRD pattern of green synthesized AgNPs.

Abbreviations: AgNPs, silver nanoparticles; XRD, X-ray diffraction.

The mortality of the mice at different concentrations of AgNP-loaded vaccines is shown in Figure 5 and Table 1. The highest percentage of viability was significantly seen at $15 \mathrm{mg} / \mathrm{kg}$ and $20 \mathrm{mg} / \mathrm{kg}$ as compared with the PBS group when analyzed by chi-square test $(P<0.05)$. Deaths in mice were confirmed by FAT using FITC-conjugated anti-nucleocapsid polyclonal antibodies. Moreover, RFFIT on the collected sera revealed that all the living mice had $>3 \mathrm{IU} / \mathrm{mL}$ of neutralizing antibody titers while dead ones had $<0.375 \mathrm{IU} / \mathrm{mL}$ of neutralizing antibodies (Table 1).

\section{Potency determination of AgNPs-loaded vaccine based on the $\mathrm{NIH}$ test}

The potency of AgNPs-containing vaccine was determined using the NIH test, and the result was simultaneously compared with the alum-containing vaccine. Table 2 shows the mortality of the mice in the NIH test. The percentage ratio of the surviving mice to the total mice that received AgNPscontaining vaccine was comparable with that of the mice

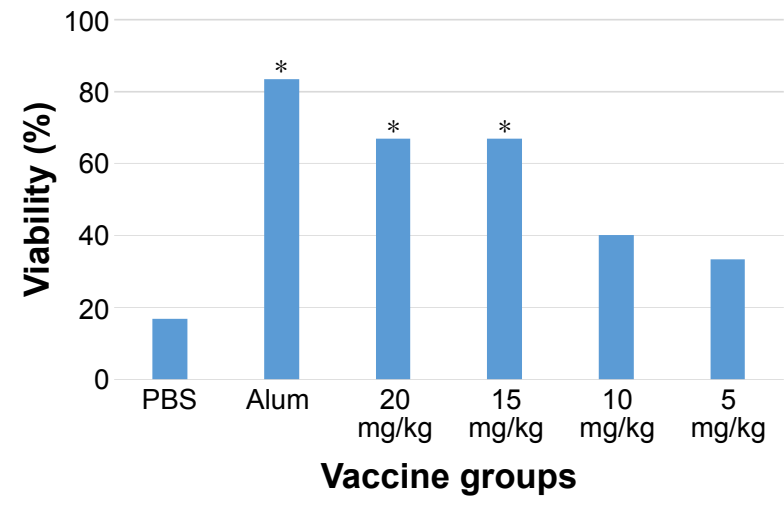

Figure 5 Survival rate of mice received inactivated rabies vaccine with different concentrations of AgNPs.

Notes: PBS and vaccine containing alum were used as negative and positive controls, respectively. The significant level was compared with the alum group using chi-square method $(* P<0.05)$.

Abbreviations: AgNPs, silver nanoparticles; PBS, phosphate buffer saline. 
Table I The mortality rate of the mice received vaccines with different concentrations of AgNPs over a period of 2 I days

\begin{tabular}{|c|c|c|c|c|c|c|c|}
\hline Group & Neutralizing antibody titer & $5 \mathrm{mg} / \mathrm{kg}$ & $10 \mathrm{mg} / \mathrm{kg}$ & $15 \mathrm{mg} / \mathrm{kg}$ & $20 \mathrm{mg} / \mathrm{kg}$ & Alum & PBS \\
\hline Survived mice & $\geq 3.00 \mathrm{IU} / \mathrm{mL}$ & 2 & 2 & 4 & 4 & 5 & 0 \\
\hline Dead mice & $\leq 0.38 \mathrm{IU} / \mathrm{mL}$ & 4 & 3 & 2 & 2 & I & 6 \\
\hline Total & - & 6 & 5 & 6 & 6 & 6 & 6 \\
\hline
\end{tabular}

Note: Commercially available vaccine containing alum and PBS was used as positive and negative controls, respectively.

Abbreviations: AgNPs, silver nanoparticles; PBS, phosphate buffer saline.

that received alum vaccine, and no significant difference was observed using chi-square statistical test (Figure 6). Statistical analysis showed that the calculated potency for alum adjuvant vaccine is 1.897 and for the AgNPs-containing vaccine, it is 1.303 . In addition, a linear relationship was found between viability and vaccine dilutions in the NIH test (Figure 7).

\section{In vitro and in vivo toxicity of the synthesized AgNPs}

The toxicity of green synthesized AgNPs was investigated both in vitro and in vivo using MTT assay and mice abnormal toxicity, respectively. In vitro toxicity of AgNPs was first evaluated by MTT assay on L929 cell line. The data demonstrated that alum at the concentration of $10 \mathrm{mg} / \mathrm{mL}$ was significantly toxic $(P<0.05)$, but AgNPs were not toxic at this concentration when compared with the control group that received PBS (Figure 8).

Abnormal toxicity test of green synthesized AgNPs was performed according to the European Pharmacopeia 8.0. All the mice did not show any abnormal reactions or signs of illness 24 hours after the time of injection (Table 3). All the animals gained weight, and the measurement of weight gain did not show any significant difference between the test and control group (Figure 9).

\section{Safety test for AgNPs-loaded vaccine}

Safety test for veterinary use was carried out on two healthy female dogs. After administration of AgNPs-loaded rabies vaccines, the animals were daily monitored for 14 days. It must be mentioned that the normal mean body temperature for a Skye Terrier dog is in the range of $38.3^{\circ} \mathrm{C}-39.2^{\circ} \mathrm{C}$ and true fever presents body temperatures ranging from $39.5^{\circ} \mathrm{C}$ to $41.1^{\circ} \mathrm{C} .{ }^{26}$ The animals did not show signs of either disease or local and systemic reactions (Table 4), and no fever or death was observed due to the vaccine during monitoring.

\section{Discussion}

One of the current issues in vaccinology is the necessity of novel adjuvants and targeted delivery systems. Adjuvants have routinely been used for both research and commercial vaccines. However, toxicity and physicochemical properties that affect manufacturability have limited their clinical applications. Recently, nanoparticles showed great promise for vaccine formulations. ${ }^{14}$ The biological functions of nanoparticles are highly dependent on dimensions and concentrations. Dimensions at the nanometric scale can precisely control and easily change the size range of viruses and are also able to capture or trap macromolecules such as proteins and nucleic acids. ${ }^{11}$ AgNPs are one of the attractive candidates for drug delivery of macromolecules such as DNA, RNA, and proteins. Many studies have had their focus on the use of AgNPs as drug carriers, and several in vitro studies revealed a little toxicity of AgNPs on various cell lines. ${ }^{27,28}$

In this study, the adjuvanticity effect of AgNPs on the rabies veterinary vaccine was assessed and the results were compared with commercially available veterinary vaccine containing alum adjuvant. AgNPs were prepared with $E$. procera extract as reducing agent from silver ions. The results showed that the size of AgNPs in water was $50-70 \mathrm{~nm}$ with a negative charge of $-14 \mathrm{mV}$. In addition, XRD results confirmed the identity of biosynthesized AgNPs.

Table 2 The mortality rate of the mice in the NIH test at each dilution for reference and alum- and AgNPs-containing vaccines

\begin{tabular}{|c|c|c|c|c|c|c|c|c|c|}
\hline \multirow[t]{2}{*}{ Dilutions } & \multicolumn{2}{|l|}{$1 / 5$} & \multicolumn{2}{|l|}{$1 / 25$} & \multicolumn{2}{|c|}{ I/I 25} & \multicolumn{2}{|c|}{$1 / 625$} & \multirow[t]{2}{*}{ Potency } \\
\hline & Live & Dead & Live & Dead & Live & Dead & Live & Dead & \\
\hline Reference & 13 & 3 & 10 & 5 & 5 & 9 & 1 & 12 & - \\
\hline Alum & 12 & 4 & 8 & 7 & 5 & 10 & 2 & 14 & I.897 \\
\hline $\mathrm{AgNPs}$ & 11 & 4 & 5 & 6 & 2 & 11 & 2 & 10 & 1.303 \\
\hline
\end{tabular}

Note: The potencies were calculated using Spearman-Karber method.

Abbreviations: AgNPs, silver nanoparticles; NIH, National Institutes of Health. 


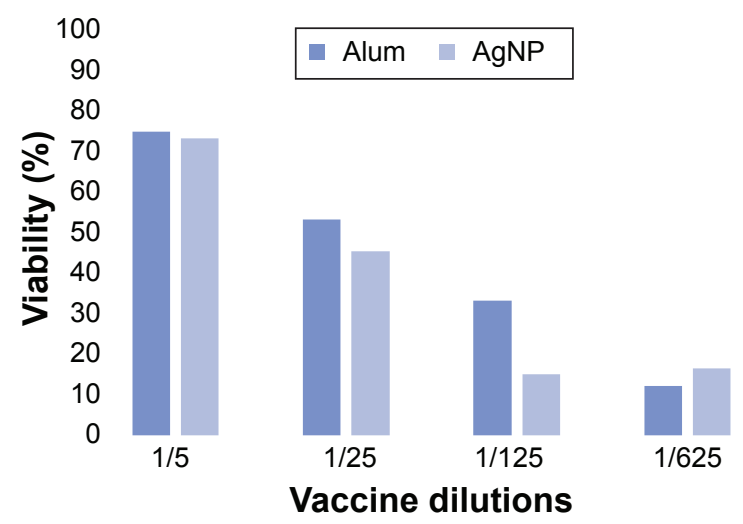

Figure 6 Comparison of mice viability (\%) between alum and AgNPs in the NIH test. Note: No significant difference was found between alum and AgNP in each dilution. Abbreviations: AgNPs, silver nanoparticles; NIH, National Institutes of Health.

The adjuvanticity effect of nanoparticles was examined by injection of fatal/challenge virus into the mice after receiving different concentrations of AgNPs and monitoring for mortality over a 21-day period. Results revealed that adjuvanticity of AgNPs was enhanced by increasing its concentration and finally reached a plateau which might be the reason for the similarity of the results obtained for the $15 \mathrm{mg} / \mathrm{kg}$ and $20 \mathrm{mg} / \mathrm{kg}$ concentrations. In addition, the mice were evaluated for neutralizing antibodies using RFFIT method. Antibody titer results were in line with the mortality percentage of the mice at different concentrations of AgNPs and were more in groups that received $15 \mathrm{mg} / \mathrm{kg}$ and $20 \mathrm{mg} / \mathrm{kg}$. Surprisingly, at these concentrations, the adjuvanticity effect is comparable with alum adjuvant. This result is similar to the report by $\mathrm{Xu}$ et $\mathrm{a}^{13}$ regarding their two protein models, namely ovalbumin and bovine serum albumin. However, this phenomenon was observed at lower concentrations for both protein models in their study $(2 \mathrm{mg} / \mathrm{kg}$ and $10 \mathrm{mg} / \mathrm{kg}$ for bovine serum albumin and ovalbumin, respectively) with AgNPs, which have a size of $141 \mathrm{~nm}$ and a charge

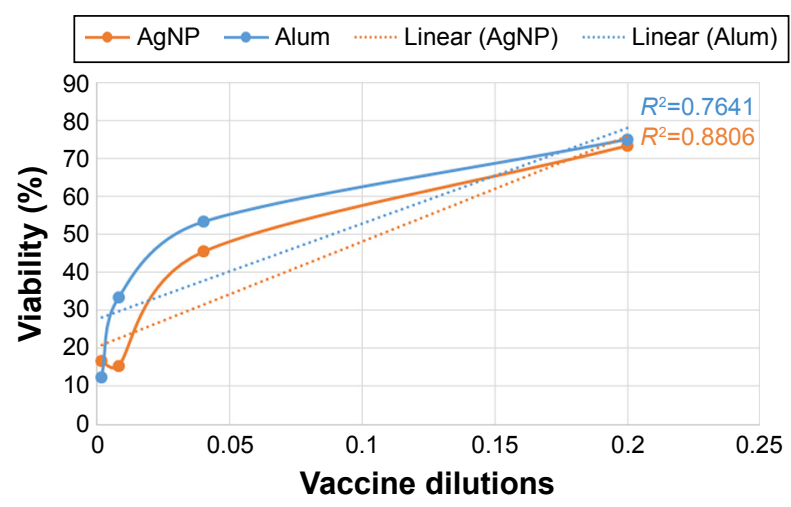

Figure 7 Linearity relationship between viability and vaccine dilutions in the NIH test. Abbreviations: AgNP, silver nanoparticle; $\mathrm{NIH}$, National Institutes of Health.

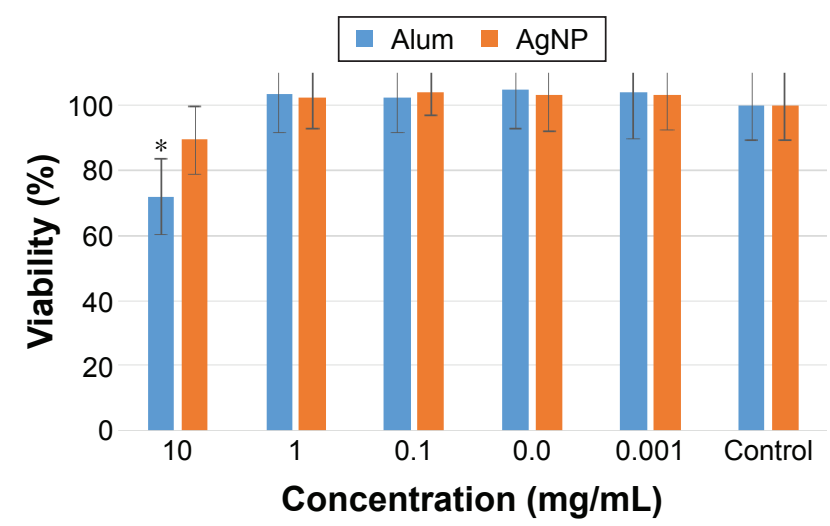

Figure 8 In vitro toxicity assay of AgNPs and alum on L929 cell line. Note: The significance level was compared with the control group $(* P<0.05)$. Abbreviation: AgNPs, silver nanoparticles.

of $-30.6 \mathrm{mV}$. The difference can be explained by the fact that the interaction of nanoparticles with proteins and cells depends on the surface properties. ${ }^{29,30}$ Furthermore, it has been reported that $\mathrm{BALB} / \mathrm{c}$ mice that ${ }^{31}$ they used have more potent humoral immune responses.

The concentration of $15 \mathrm{mg} / \mathrm{kg}$ AgNPs was further analyzed by the NIH test for potency calculation and comparison with alum adjuvant. It must be noted that the NIH test is a gold standard method for testing potency of rabies vaccine. The NIH results elucidated that the potency of vaccine containing nanoparticles was comparable with the commercial vaccine containing alum (the same batch), and both are acceptable by WHO as potent animal vaccines. In addition, the mortality of mice correlates with the dilution factor used in the NIH test. It must be emphasized that when different dilutions of vaccine were prepared, the adjuvanticity effect of AgNPs in the diluted vaccines was not affected. This indicates that AgNPs were homogeneously mixed with the antigen, and the interaction between the inactivated rabies virus and the nanoparticle was not affected by dilution. When the survival rate with the dilution of 1/5 NIH test (received $3 \mathrm{mg} / \mathrm{kg}$ of AgNPs) was compared with the survival rate in the concentration of $5 \mathrm{mg} / \mathrm{kg}$ of nanoparticle (at the initial test of the study), surprising results were obtained. When the vaccine was diluted to one part in five, the survival rate was $73.3 \%$, whereas when the nanoparticle with $5 \mathrm{mg} / \mathrm{kg}$ concentration was injected, the survival rate was equivalent to $33.3 \%$. This phenomenon can be explained as follows: when the vaccine was diluted by the NIH buffer, the antigen was also diluted and the ratio of nanoparticle/antigen was not changed. In other words, one of the reasons why the mortality of mice at $5 \mathrm{mg} / \mathrm{kg}$ per dose is higher than that of $3 \mathrm{mg} / \mathrm{kg}$ per dose is that, at this concentration, the ratio of 
Table 3 Abnormal reactions and signs of illness in mice monitored for 24 hours after the injection of $300 \mu \mathrm{g}$ of AgNPs

\begin{tabular}{|c|c|c|c|}
\hline Criteria & Yes/no & Criteria & Yes/no \\
\hline Weight loss & No & Loss of fur and hair & No \\
\hline Loss of appetite & No & $\begin{array}{l}\text { Change in skin, eye, mucus } \\
\text { membrane color }\end{array}$ & No \\
\hline Inappetence & No & Diarrhea & No \\
\hline Dehydration & No & Dehydration & No \\
\hline Hunched posture & No & Salivation & No \\
\hline Ruffled fur coat & No & Nasal discharge & No \\
\hline Staining of fur coat & No & Changes in blood pressure & No \\
\hline Gasping for breath & No & Lethargy & No \\
\hline Internal bleeding & No & $\begin{array}{l}\text { Substantial distress from } \\
\text { shock and extensive trauma }\end{array}$ & No \\
\hline Aggression & No & $\begin{array}{l}\text { Companion by violent and } \\
\text { rapid leg and body movements }\end{array}$ & No \\
\hline Tremors & No & Collapse & No \\
\hline Convulsions & No & Coma & No \\
\hline
\end{tabular}

Abbreviation: AgNPs, silver nanoparticles.

antigen/nanoparticles is not appropriate. From this inconsistency, it can be concluded that not only nanoparticle concentration but also the ratio of nanoparticles/antigen is very important in adjuvanticity function of AgNPs. The importance of antigen/nanoparticle ratio to AgNPs is more practical when the mice survival at 1:25 dilution (mice that actually received $600 \mu \mathrm{g} / \mathrm{kg}$ of AgNPs) is still higher than at the concentration of $5 \mathrm{mg} / \mathrm{kg}$ in adjuvanticity test $(45.45 \%$ vs $33.3 \%$, respectively).

The mechanism of AgNP adjuvanticity is not clearly known. However, according to the antigen-nanoparticle ratio and accumulation properties of nanoparticles in water, the main mechanism may be trapping and sustained release of the antigen by AgNPs which leads to better stimulation

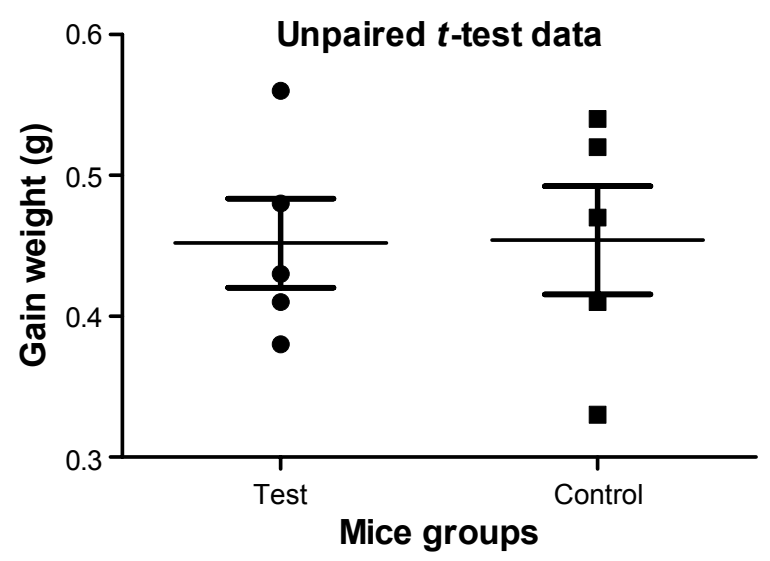

Figure 9 Weight gain of mice after the injection of $300 \mu \mathrm{g}$ of AgNPs.

Note: Analysis of data showed no significant difference between the test and control groups $(P$-value $=0.9166)$.

Abbreviation: AgNPs, silver nanoparticles.
Table 4 Abnormal reactions and signs of illness in dogs monitored for 14 days after the injection of AgNPs-loaded rabies vaccines

\begin{tabular}{llll}
\hline Criteria & Yes/no & Criteria & Yes/no \\
\hline Anaphylaxis & No & $\begin{array}{l}\text { Discomfort and swelling } \\
\text { at the injection site }\end{array}$ & No \\
$\begin{array}{llll}\text { Sudden onset of diarrhea } \\
\text { Vomiting }\end{array}$ & No & $\begin{array}{l}\text { Fever or mild fever } \\
\text { Decreased or lack of } \\
\text { appetite and food intake }\end{array}$ & No \\
Shock & No & Decreased body mass & No \\
Seizures & No & Decreased activity & No \\
Lethargy & No & Soreness & No \\
Hair loss & No & Stiffness & No \\
Hair color change & No & Conjunctivitis & No \\
Rarely lameness & No & Sneezing & No \\
Coma & No & Oral ulcers & No \\
\hline Ab & & &
\end{tabular}

Abbreviation: AgNPs, silver nanoparticles.

of innate immune system. Moreover, there are also many studies showing that AgNPs directly stimulate the innate immune system. Research suggests that they act through several mechanisms such as inflammatory cytokines release, ${ }^{32,33}$ recruitment of leukocytes, and upregulation of major histocompatibility class II molecules on peritoneal macrophages. ${ }^{13}$

Although, the toxicity of silver ions had been previously proven by in vitro and in vivo tests, no toxicity was observed for AgNPs in this study. In the current study, the in vitro toxicity of AgNPs and alum on L929 cell line was evaluated using MTT assay and it was found that alum is toxic at the concentration of $10 \mathrm{mg} / \mathrm{mL}$, but $\mathrm{AgNP}$ is not toxic at this concentration. This might be due to the negligible release of silver ions from AgNPs. ${ }^{13}$ Moreover, in the current study, the toxicity of AgNPs was also investigated in vivo according to the European Pharmacopeia 8.0. The AgNPs were injected alone and in combination with the vaccine in mice and dogs and clinical signs were monitored in the animals. The results showed that AgNPs at a concentration of $15 \mathrm{mg} / \mathrm{mL}$ did not exert any in vivo toxic effect.

\section{Conclusion}

The adjuvanticity effect of AgNPs on rabies vaccine potency was shown for the first time. These results require further assessment using different routes of injections as well as different animal models. Furthermore, the AgNP adjuvanticity should be tested with a wide range of antigens and its mechanism of action needs to be clarified. The results of this study are consistent with those of other studies, which clearly showed the effect of AgNPs on increasing the humoral response to the rabies vaccine. 


\section{Acknowledgment}

The authors are grateful to the WHO Collaborating Center for Reference and Research on Rabies of Pasteur Institute of Iran.

\section{Disclosure}

The authors report no conflicts of interest in this work.

\section{References}

1. Finke S, Conzelmann KK. Replication strategies of rabies virus. Virus Res. 2005;111(2):120-131.

2. Bahloul C, Taieb D, Kaabi B, et al. Comparative evaluation of specific ELISA and RFFIT antibody assays in the assessment of dog immunity against rabies. Epidemiol Infect. 2005;133(4):749-757.

3. Knobel DL, Cleaveland S, Coleman PG, et al. Re-evaluating the burden of rabies in Africa and Asia. Bull World Health Organ. 2005 83(5):360-368.

4. Moore SM, Hanlon CA. Rabies-specific antibodies: measuring surrogates of protection against a fatal disease. PLoS Negl Trop Dis. 2010; 4(3):e595.

5. Finnegan CJ, Brookes SM, Johnson N, et al. Rabies in North America and Europe. J R Soc Med. 2002;95(1):9-13.

6. Lindblad EB. Aluminium compounds for use in vaccines. Immunol Cell Biol. 2004;82(5):497-505.

7. Wang W, Singh M. Selection of adjuvants for enhanced vaccine potency. World J Vaccines. 2011;1(2):33-78.

8. Sivakumar SM, Safhi MM, Kannadasan M, Sukumaran N. Vaccine adjuvants - current status and prospects on controlled release adjuvancity. Saudi Pharm J. 2011;19(4):197-206.

9. Petrovsky N, Aguilar JC. Vaccine adjuvants: current state and future trends. Immunol Cell Biol. 2004;82(5):488-496.

10. He Q, Mitchell AR, Johnson SL, Wagner-Bartak C, Morcol T, Bell SJ. Calcium phosphate nanoparticle adjuvant. Clin Diagn Lab Immunol. 2000;7(6):899-903.

11. Zhao L, Seth A, Wibowo N, et al. Nanoparticle vaccines. Vaccine. 2014;32(3):327-337.

12. Dykman LA, Staroverov SA, Bogatyrev VA, Shchyogolev SY. Adjuvant properties of gold nanoparticles. Nanotechnol Russ. 2010; 5(11-12):748-761

13. Xu Y, Tang H, Liu JH, Wang H, Liu Y. Evaluation of the adjuvant effect of silver nanoparticles both in vitro and in vivo. Toxicol Lett. 2013; 219(1):42-48.

14. Akagi T, Baba M, Akashi M. Biodegradable nanoparticles as vaccine adjuvants and delivery systems: regulation of immune responses by nanoparticle-based vaccine. In: Kunugi S, Yamaoka T, editors. Polymers in Nanomedicine. Vol. 247. Berlin, Heidelberg: Springer; 2012:31-64.

15. Malyala P, Singh M. Micro/nanoparticle adjuvants: preparation and formulation with antigens. In: Davies G, editor. Vaccine Adjuvants. Methods and Protocols. Totowa, NJ: Humana Press; 2010:91-101.
16. Horikoshi S, Serpone N, editors. Introduction to nanoparticles. Microwaves in Nanoparticle Synthesis. Weinheim: Wiley-VCH Verlag GmbH \& Co. KGaA; 2013:1-24.

17. Rahimi-Nasrabadi M, Cohan RA, Sadat Shandiz SA. Optimization of biological synthesis of silver nanoparticles using plant extract of Eucalyptus. The Third Congress of Defense Applications of Nanoscience. Tehran: Imam Hossein University; 2013.

18. Reed LJ, Muench H. A simple method of estimating fifty per cent endpoints. Am J Epidemiol. 1938;27(3):493-497.

19. Meslin F-X, Kaplan MM, Koprowski H, Organization WH. Laboratory Techniques in Rabies. Geneva: Citeseer; 1996.

20. Commission BP, Council GM, Commission GBM. British Pharmacopoeia. London: Her Majesty's Stationery Office; 2015.

21. Pharmacopoeia CotEoaE. Rabies Vaccine (Inactivated) for Veterinary Use. Strasbourg: Council of Europe; 2015.

22. Pharmacopeia US. USP 38-NF 33. US Pharmacopeial Convention: Rockville, MD; 2015.

23. Aldinger KA, Sokoloff G, Rosenberg DM, Palmer AA, Millen KJ Genetic variation and population substructure in outbred CD-1 mice: implications for genome-wide association studies. PLoS One. 2009; 4(3):e4729.

24. Fillman-Holliday D, Everitt J. Animal care and use in toxicity testing. In: McQueen CA, editor. Comprehensive Toxicology (Second Edition). Oxford: Elsevier; 2010:97-115.

25. Moore GE, Guptill LF, Ward MP, et al. Adverse events diagnosed within three days of vaccine administration in dogs. $J$ Am Vet Med Assoc. 2005;227(7):1102-1108.

26. Dunn J, Gorman N. BSAVA EDUCATION COMMITTEE COMMISSIONED ARTICLE Fever of unknown origin in dogs and cats. J Small Anim Pract. 1987;28(3):167-181.

27. De Jong WH, Borm PJ. Drug delivery and nanoparticles: applications and hazards. Int J Nanomedicine. 2008;3(2):133-149.

28. Brown PK, Qureshi AT, Moll AN, Hayes DJ, Monroe WT. Silver nanoscale antisense drug delivery system for photoactivated gene silencing. ACS Nano. 2013;7(4):2948-2959.

29. Verma A, Stellacci F. Effect of surface properties on nanoparticle-cell interactions. Small. 2010;6(1):12-21.

30. Saptarshi SR, Duschl A, Lopata AL. Interaction of nanoparticles with proteins: relation to bio-reactivity of the nanoparticle. J Nanobiotechnology. 2013;11(1):26.

31. Watanabe H, Numata K, Ito T, Takagi K, Matsukawa A. Innate immune response in Th1- and Th2-dominant mouse strains. Shock. 2004;22(5): 460-466.

32. Park EJ, Bae E, Yi J, et al. Repeated-dose toxicity and inflammatory responses in mice by oral administration of silver nanoparticles. Environ Toxicol Pharmacol. 2010;30(2):162-168.

33. Park J, Lim DH, Lim HJ, et al. Size dependent macrophage responses and toxicological effects of $\mathrm{Ag}$ nanoparticles. Chem Commun (Camb). 2011;47(15):4382-4384.
International Journal of Nanomedicine

\section{Publish your work in this journal}

The International Journal of Nanomedicine is an international, peerreviewed journal focusing on the application of nanotechnology in diagnostics, therapeutics, and drug delivery systems throughou the biomedical field. This journal is indexed on PubMed Central, MedLine, CAS, SciSearch ${ }^{\circledR}$, Current Contents ${ }^{\circledR} /$ Clinical Medicine,

\section{Dovepress}

Journal Citation Reports/Science Edition, EMBase, Scopus and the Elsevier Bibliographic databases. The manuscript management system is completely online and includes a very quick and fair peer-review system, which is all easy to use. Visit http://www.dovepress.com/ testimonials.php to read real quotes from published authors. 